\title{
COLLABORATIVE WORKING AND CONTESTED PRACTICES: FORMING, DEVELOPING AND SUSTAINING SOCIAL PARTNERSHIPS IN EDUCATION
}

\author{
Stephen Billett and Carolyn Ovens (Griffith University) \\ Allie Clemans and Terri Seddon (Monash University)
}

\begin{abstract}
Despite a lack of applied research, social partnerships are increasingly being adopted by both government and non-government agencies to meet localised needs in education and other fields. This paper discusses the findings of an investigation of how social partnerships can best be formed, developed and sustained over time. Earlier work identified partnerships arising from community concerns, governmental enactment and negotiation between community and government agencies. However, across these distinct kinds of social partnerships, the partnership work that was central to their operation was particularly relevant. In the study reported here, researchers engaged with 10 longstanding social partnerships to elicit, synthesise and verify the principles and practices underpinning their work. The principles and practices that are proposed as most likely to assist the effective formation, development and transformation of social partnerships over time comprise building and maintaining: (i) shared goals; (ii) relations with partners; (iii) capacity for partnership work; (iv) governance and leadership; and (v) trust and trustworthiness. These principles stand as ideals and goals to guide the development and continuity of social partnerships that can support important educational initiatives, and provide bases for evaluating partnership work. However, rather than being benign, this work and these practices are often underpinned by contested relations as much as collaborative work.
\end{abstract}

\section{Building education through social partnerships}

Governments, civic organizations and aid agencies worldwide are increasingly looking to social partnerships as means to understand and address local and regional concerns and for building social capital. This interest extends to and includes partnerships associated with vocational education and training, that are often enacted to address issues or as means to secure effective educational provisions through meeting localised needs (e.g. Taylor, 2006). In this way, social partnerships are held to comprise localised networks that connect some combination of local community groups, education and training providers, industry and government to work on local issues and community-building activities (Rees, 1997; Seddon $\&$ Billett, 2004). These partnerships bring the prospect of engaging communities with government and non-government agencies in identifying and solving problems in ways consistent with localised needs and concerns (Field, 2000), making informed and consensus-based decisions, and cooperatively negotiating locally desirable outcomes (Seddon, Billett \& Clemans, 2005). They are also seen as a way to assist collaborative decision-making and build local capacity (Jessop, 1998) that supports economic, social and civic development (Putman 1993) attuned to local needs and circumstances (United Nations Development Program (UNDP), 1997), and to militate against a reliance upon central agencies. These capacity-building and developmental goals are well aligned to educational initiatives, particularly those that are required to engage effectively and collaboratively with 
those outside of educational institutions, such as managing school-to-work transitions (Billett, 2000). By its very nature, a partnership requires partners to collaborate in achieving common goals. However, even when there are a common set of concerns, the process of working together is complex and challenging, often contested and requiring new ways of working and, in changing circumstances. Therefore, to be effective, social partnerships require partners and participants to understand that social partnerships work in ways directed towards achieving shared goals or, more likely, a common focus of concern (Coffield, 2000). However, it is likely that even when there are shared goals, the means of securing those goals will be the subject of contested views and practices within social partnerships, which can jeopardize their formation and continuity and the important work they are assigned (Cardini, 2006). Given this is complex and contested, but important, work, the goal here is to understand the effective conduct of partnership work in order to develop and guide its practice, and evaluate its enactment.

To this end, this paper discusses the procedures and findings of a project that investigated the formation, development and continuity of 10 existing social partnerships in Australia. The aim was to understand how best social partnerships might be initiated and developed in supporting vocational education initiatives. The aim was to identify principles and practices that are effective in supporting their formation, initial development and continuity over time and through change. To do this, the workings and achievements of the 10 social partnerships were investigated to identify those factors that shaped or inhibited their development, including how issues of contestation were addressed within them.

In the following sections, the contexts for social partnerships are reviewed to understand why social partnerships are being enacted by both government and nongovernment agencies to secure their programs and purposes. Next, the approach adopted for this study is briefly overviewed and the 10 social partnerships that are the focus of the study are introduced. Then, the conceptions of social partnership work are discussed and the five dimensions of partnership work and principles and practices constituting effective partnership work are described, and their premises discussed. These are building and maintaining: (i) shared purposes and goals; (ii) relations with partners; (iii) capacities for partnership work; (iv) partnership governance and leadership, and (v) trust and trustworthiness.

\section{Context for social partnerships}

As foreshadowed, government and non-government agencies across the globe are now viewing social partnerships as a means of improving service delivery and for building enhanced capability at the local level (e.g., Green, Wolf \& Lehney, 1999; UNDP, 1997). These agencies are also promoting social partnerships as ways of managing risk in policy areas where government has depleted or limited resources. In Australia, they have been adopted by government because of various concerns and needs, particularly the growing imperatives for: (a) a de-centering of policy formation and enactment - the concern that centralised agencies struggle to understand and accommodate the diverse needs of communities they aim to serve, such as in providing effective and tailored educational provisions for young people (e.g. O’Donoghue, 2001); (b) local capacity buildinggovernmental interest in building capacity at the local level to assist in the effective targeting and delivery of service provisions, such as VET courses and provisions (e.g., Kosky, 2001); (c) meeting local needs-finding ways of securing economic goals through local partnerships and decision making, such as aligning VET provisions with local 
enterprise needs (e.g., ANTA, 2003); and (d) local engagement-governmental interest in engaging and mobilising individuals and communities more directly in civic activity and community building projects (Field, 2000). This interest was also likely motivated by political concerns about the rise of independent (i.e. non-party) representatives in both federal and state parliament and fringe parties (e.g. One Nation) who found support within communities (in regional Australia and on the fringes of its cities) that felt ignored and marginalized by central government and agencies.

So, economic, social and political imperatives and goals intermingle with and underpin government and non-government agencies' interest in the effective enactment of social partnerships at a local level. These partnerships are also viewed as being desirable and as potential solutions to complex policy problems, including the potential means for de-centering decision making and securing timely and pertinent policy advice. However, the formation and ongoing development of these social partnerships can be complex, vexed and inherently contested (Cardini, 2006; Taylor, 2006), thereby likely requiring particular kinds of support and guidance, as well as particular kinds of actions by and sentiments of participants. This may well include government, other agencies and participants giving away something of their power, control and interest in order to assist the building and sustaining trust in the operation of the partnerships (Billett \& Seddon, 2004). Yet, these partnerships need to be characterised as being both collaborative and contested in their attempts to achieve localized goals.

Much can be learnt about the development of social partnerships on the basis of a consideration of their origins and their auspicising or hosting. Some social partnerships evolve as a product of local concerns (Billett, 2000). These include concerns about local skill shortages, youth unemployment, lack of adequate social and physical infrastructure or concerns about promoting local regions and communities, and also the development of local businesses. Because the geneses of these kinds of partnerships are often aligned with local issues, they are referred to as 'community partnerships' (Billett \& Seddon, 2004). An example of a community partnership in this study was the actions of a community, in an outlying district of large city. As a result of concerns about the lack of social infrastructure (e.g. transport) and educational and employment opportunities for its young people, the community collaborated in presenting its concerns to and engaging with government to address these issues.

Then, there are social partnerships that government and non-government agencies are intentionally establishing and enacting for specific policy purposes. We refer to these as 'enacted partnerships', because the interests which seek to enact them are often outside communities in which they are enacted. These partnerships are of a different kind from those that emerge spontaneously from a locally identified need (Seddon \& Billett, 2004). This is partly because they are enacted by agencies external to the community, and are often more global in their ambitions, more inclusive in their membership, and wider in their localities. They also likely carry particular mechanisms and demands for accountabilities that can serve to shape the development and nature of the partnership work. For instance, Local Learning and Employment Networks (LLENs) were established by the Victorian state government to address issues of school-to-work transitions. These issues arose from an enquiry into young people in the state failing to secure an effective post-school transition to either paid employment or further education (Kosky 2001). The government divided the state into a number of regions and in each funded LLENs to assist in facilitating post-school transitions through partnerships among community, educational institutions, 
industry and local government. However, enacted social partnerships such as LLENs are subject to governmental administrative and accountability measures that may constrain their activities and practices in ways bound up in their operation and administration. Moreover, as these kinds of partnerships are enacted from outside the community, their formation is often predicated upon and auspiced (i.e. hosted) through an existing network or affiliations. For instance, local government played an auspicising role with a number of LLENS. So, while governments and the government agencies might seek to select and coopt such networks or affiliations to achieve their policy goals, this may well require negotiation with and, possibly, transformation of existing partnerships. Consequently, there may be contestation between interests and concerns of external sponsors (e.g. government) and the localised interests in which the partnership is being enacted. However, within the LLENs, government is able to apply leverage through its provision of financial sponsorship and employment of some staff, and specification of membership categories.

Both 'community' and 'enacted' partnerships, but particularly the latter, are often hosted or auspiced by a local organization or agency. The nature of this auspicing can influence how the social partnership develops and is governed. For instance, an earlier study (Billett \& Seddon, 2004) identified social partnerships that had been auspiced by local government; this meant that many of the participants were associated with local government activities and processes, and priorities. Consequently, as the concept of consensus-based decision making was well established, some of these skills did not need to be developed by those engaged in the partnership. Yet, there were also localized and politicized lobbying and persuasion behind the scenes to secure 'consensus' at meetings (Seddon, Billett \& Clemans, 2005). So although these partnerships quickly moved through the early stages of formation and development, local political factors provided particular kinds of constraints on participants and processes of participation.

In another partnership, the auspicing organization was more able to shape the nature of the partnership with central agencies, which made it quite distinct from enacted partnerships. Here, an Indigenous community group elected to reject a government-initiated and funded social partnership because the group believed its purposes were against their community interests. Eventually, a partnership was established, but on the community's terms. This then can be seen as a partnership negotiated between the needs of the community and the enacting agency, referred to here as a 'negotiated partnership'. From this example it seems that these kinds of partnerships are likely to be well developed and confident about their purposes and priorities. Yet, other evidence suggests that there may be only a few partnerships easily able to resist government funding (Billett \& Seddon, 2004).

The different bases for the initial formation of social partnerships provide a typology that is particularly pertinent to understanding the goals and processes of these three different kinds of social partnership are quite distinct. For instance, as depicted in Table 1, the goals for 'community' partnerships are often associated with securing resources to address localized needs, whereas those for 'enacted' partnerships might be about securing policy goals of the sponsoring agency and the centre. Moreover, the processes likely to be adopted by these social partnerships may be quite distinct. For instance, 'community' partnership processes might be focused on engaging with and trying to influence external agencies to achieve locally derived goals or concerns. In this way, the processes might have a strong emphasis on engaging with parties external to the local community or sets of concerned local interests. Conversely, the process engaged by 
'enacted' partnerships might be towards developing effective partnerships at the local level, to secure government initiatives.

Table 1: Origins and characteristics of partnerships

\begin{tabular}{llll}
\hline Types & \multicolumn{1}{c}{ Genesis } & \multicolumn{1}{c}{ Goals } & \multicolumn{1}{c}{ Processes } \\
\hline $\begin{array}{l}\text { Community } \\
\text { partnership }\end{array}$ & $\begin{array}{l}\text { Concerns, problems, issues } \\
\text { identified within the } \\
\text { community }\end{array}$ & $\begin{array}{l}\text { To secure resources to } \\
\text { address issues, problems } \\
\text { and concerns, often from } \\
\text { agencies outside the } \\
\text { community }\end{array}$ & $\begin{array}{l}\text { Consolidating and making } \\
\text { a case and then working } \\
\text { with external agencies to } \\
\text { secure adequate responses }\end{array}$ \\
\hline $\begin{array}{l}\text { Enacted } \\
\text { partnership }\end{array}$ & $\begin{array}{l}\text { From outside the } \\
\text { partnership which is to be } \\
\text { the target of the } \\
\text { engagement, yet with goals } \\
\text { or resources that the } \\
\text { community is interested in } \\
\text { engaging with }\end{array}$ & $\begin{array}{l}\text { To secure outcomes aligned } \\
\text { to external funding body }\end{array}$ & $\begin{array}{l}\text { Responding to } \\
\text { requirements and } \\
\text { accountabilities of external } \\
\text { partner/sponsor through } \\
\text { engaging the community in } \\
\text { activities associated with } \\
\text { those goals }\end{array}$ \\
\hline $\begin{array}{l}\text { Negotiated } \\
\text { partnership }\end{array}$ & $\begin{array}{l}\text { Need to secure a provision } \\
\text { of service or support that } \\
\text { necessitates working with } \\
\text { partners }\end{array}$ & $\begin{array}{l}\text { To develop effective } \\
\text { working relations outside of } \\
\text { the organisation that } \\
\text { comprises the social }\end{array}$ & $\begin{array}{l}\text { Working with and finding } \\
\text { reciprocal goals with } \\
\text { partners }\end{array}$ \\
& $\begin{array}{l}\text { partnership } \\
\end{array}$ & & \begin{tabular}{l} 
\\
\hline
\end{tabular}
\end{tabular}

It follows that the processes for the effective formation, development and maintenance of these partnerships are both potentially complex and differentiated by their origins, their auspicing and kinds of negotiations that shape their formation. For instance, in the LLENs the prospects for the development of consensual decision making were found to be premised upon and constrained by the scope of the partnerships, the diversity of interests represented within the partnership and local community, inclusion in decision making and securing local representation, and the participants' experience in consensus-based decision making (Seddon et al., 2002). Moreover, within the LLEN partnerships, like many other partnerships, there was reliance upon volunteer effort. This voluntary effort takes a number of forms. There are those who volunteer their time personally and make individually based decisions about their involvement. Then, there are those volunteers who represent agencies, enterprises, or institutions that are a member of the social partnership. The first kind of voluntary participation is premised upon the agency of individuals, their interests and their energies. Yet, because they are not dependent upon the social partnership they may resist more strongly than others the demands of sponsors. Moreover, given the engagement is premised on their interests and their energies, there are constant threats that these will be exhausted and they will withdraw. Conversely, the second kind of voluntary participation can take the form of monitoring the activities with the social partnership to represent or bulwark the interests of the institution these volunteers represent rather than the purposes and processes of social partnership (Billett \& Seddon, 2004). Although it is essential, the voluntary effort of both kinds adds further complexities to the establishment, development and maintenance of social partnerships since their decision making may be influenced by either the interests of their sponsoring institution or their personal agendas and energies. Also, the volunteers may not be directly subject to the edicts of the social partnership or any sponsoring agency. Moreover, as they elect how and when they participate and for what purpose, they are prone to exhaustion and may represent a high turn over of 
participants. Therefore, while they are less subject to the whims and demands of central agencies than are paid employees or organisations dependent upon government funding, they might be in need of replacement and/or renewal more frequently. So, as Cardini (2006) proposes, participation in social partnerships can be subject to negotiated and contested relations premised on both personal and institutional imperatives.

Consequently, the processes of building and sustaining trust, genuine engagement and progress that reflect personal or local concerns are required to sustain and engage the 'volunteer' participants. So, regardless, partnership work likely proceeds in ways that are subject, in part, to contestation among institutional and individual partners and members, which is not surprising given the often complex relations, histories and competing interests of individuals and institutions that are represented in the social partnerships. For instance, with the LLENs, many of the agencies asked to collaborate through the social partnerships were also engaged in competition with other agencies and institutions to secure increasingly scarce funds and programs. Hence, there is a need to accept and acknowledge the need to balance institutional interests with the goals and outcomes of collaboration (Taylor, 2006).

From this earlier research (Billett \& Seddon, 2004), it was concluded that while potentially being able to: (a) make significant contributions to localised decision making in VET; (b) support local initiatives associated with skill development; and (c) participate in and guide the development of local capacity-building through and for vocational education, these partnerships are themselves in need of support and guidance in their initial development and continuity. In particular, the agencies sponsoring enacted partnerships need to conduct themselves in ways that best support the prospect of effective partnership development and assist them to promote capacity building at the local level. From the perspectives of both the social partnerships (i.e., their leaders, paid employees, members, and participants) and their sponsors, the work of social partnerships, their sponsors and auspicers needs to be informed by principles and practices to guide and support the development of social partnerships and avoid repeating mistakes that may jeopardize their formation and continuity. Similarly, community and negotiated partnerships need to proceed in ways that secure positive outcomes for their constituents, and be guided by practices likely to secure those outcomes. To this end, the project reported here sought to identify the kinds of practices and principles that can assist the formation and continuity of social partnerships, including how the contested relations among them might be better understood and accommodated to achieve important goals that are set for them.

\section{Identifying principles and practices of effective partnership work}

Ten Australian social partnerships that had a history of operation and, by degrees, had experienced changes in their circumstances and goals, were selected to inform this project. They comprised different kinds of social partnerships, with particular purposes and in diverse locations. Some are examples of 'enacted partnerships' - partnerships initiated and sponsored by agencies external to the communities in which they are located (e.g., the LLENs); some are 'community partnerships' - those that were initiated by the community (e.g., a community youth program; a coalition of healthcare workers) and some are best characterised as being initiated through interaction between internal and external interests (e.g., a regional skill development project) - 'negotiated partnerships'. Although all the partnerships are concerned with addressing localised needs and capacity building, they have particular purposes. The common goal for these partnerships is about transforming 
individuals and communities through individual learning and community capacity-building activities. However, the partnerships have as their focus diverse concerns about young people's transition from school to work or study life, healthcare provisions in regional communities, skill development for extractive industries, and the provision of social infrastructure to support community development. The partnerships collectively are located in inner metropolitan areas, provincial centres, outer suburbs of metropolitan cities, and remote regional centres.

'Community' partnerships, represented in this study had been in operation for up to three years. Their work is directed towards improving the employment and educational prospects for disadvantaged social groups and improving school retention by providing young people with a vocational Year 12 program provided through a community centre. Some partnerships aim at connecting young people to employment and work placements, while a coalition of health workers partner and make decisions about training priorities for the disability sector, including parents and carers.

The 'enacted' partnerships include some of the LLENs that focus on creating pathways to training and employment for young people disengaged from education and training. These local learning and employment networks were established in Victoria in 2001 and continue to operate through a group of community stakeholders who come together to plan and initiate pathways and programs for youth, at the regional level. However, their continuity is in part premises on government commitment, and the expectation by government that these partnerships will become increasingly self-funded agencies.

The 'negotiated' partnerships include a Catholic college with a major work placement and transition program, and a community services and health coordinating agency. These social partnerships have been in operation for around 11-15 years, relatively longer than many of the 'enacted' social partnerships described above. Hence, they may be in a stronger position when negotiating with external sponsors, than those partnerships that are dependent upon sponsors for their existence.

Although not all of these social partnerships were directly associated with vocational educational provisions, the key concern for this project was to learn from them about the workings of social partnerships in order to inform those specifically associated with supporting educational and training initiatives.

Data were gathered through interviews with informants in key roles within each social partnership. The informants included those employed within the partnership and those in the community who engage with the partnership (see Billett, Clemans \& Seddon, 2005). The interviews were structured to elicit information about the development of the social partnership from their early formation to their current manifestations and goals. The interview used specific events in the life of the partnership to identify factors that sustained or undermined the partnership and its work. The data were used to construct a case study of each partnership's initial formation, early development and processes that worked to sustain it over time. Analyses of the data gathered from interviews identified guiding principles in developing partnership work, including dimensions of that work. The analysis consisted of a process of identifying recurring themes referred to across the data from the social partnerships and practices that were deemed to be effective in support and partnership work. The principles and practices and dimensions of partnership initially identified through the interview data were then returned to the 10 participating social partnerships for verification. This verification was conducted using a survey instrument that 
presented the identified set of tentative practices and principles each with a Likert scale that allowed participants in the partnership to rate their utility and current level of application in their social partnership, including the option to indicate where it was not applicable. In addition, the informants were asked to provide other principles and practices not included in those listed. The practices and principles verified in this way are presented and discussed here.

\section{Partnership work and principles and practices}

In overview, the key findings of this study include delineating dimensions of partnership work and the identification of principles and practices that support the development and continuity of social partnerships. These are discussed in turn.

\section{Partnership work}

As described above, the 10 partnerships were initially categorised as being either 'community', 'enacted' or 'negotiated' partnerships, on the basis of their origins, purposes and focus for their work (Billett \& Seddon, 2004; Seddon \& Billett, 2004). However, while these three categories of social partnership provide a means to understand different motivations, goals and processes and early development, the data also suggest that these characteristics and qualities reflect only particular and early moments in the life of social partnerships. For instance, negotiated social partnerships are likely to be well-established and able to negotiate with external agencies on mature bases and with a clear sense of their own priorities. Certainly, it is necessary to understand how they work to articulate and demonstrate a common need to negotiate and realise a shared set of concerns or goals that have to be met collectively, and through partnerships with others who can potentially contribute different kinds of resources. Participants within partnerships typically refer to this process as building trust in others as a basis for effective engagement and participation. We have called this process of building relationships of trust and working together to achieve common goals partnership work. For instance, one way in which trust has been built is through particular partners giving up something in order to sustain or support the partnership. Therefore, to understand how partnerships operate to secure these goals and respond to changing circumstances and new goals and priorities, it is necessary to go beyond these three categories of partnership origins.

Through a consideration of the informants' accounts of the formation and development of the 10 social partnerships, the salience of 'partnership work' emerged. Partnership work is held to be the interactive and collaborative process of working together to identify, negotiate and articulate shared goals, and to develop processes for realising and reviewing those goals (Billett et al., 2005). The degree to which this partnership work is directed towards shared concerns was found to be central to the workings of social partnerships. Ideally, effective partnership work embraces and harnesses the contributions of local partners and external agencies, their interactions and transformations in the collective work of realising shared goals. The processes of working together in this way have the potential for:

- communities to identify and represent their needs, and to secure quality partners and partnership arrangements that will enable them to achieve their objectives; and

- government and non-government agencies to understand and respond to local needs, to utilise local resources and enhance capacity for local governance. 
Because of the potential for particular interests and contestations to erode or capture the focus of social partnerships, it is necessary to understand how they might work to achieve these potentials. From analyses of the interview data of informants from the 10 social partnerships, it was concluded that partnership work is a critical and ongoing process in social partnerships. It contributes to the consolidation of relationships of trust and working as a partner. However, the process of trust building is unlikely ever to be complete or without threat to its erosion. It is continually being enacted, negotiated and remade throughout the life of the partnership, albeit in different ways and by different degrees in the changing circumstances of and goals for these partnerships. Consequently, participants must continue to work at relationship building if trust is to be developed and maintained between the partners.

Seeing social partnerships from a process perspective emphasizes these practices as an outcome of partnership work as well as being dependent upon it. Focusing on instances of relatively successful partnership work offers the prospect of identifying useful approaches for understanding the complexity and diversity of social partnerships' working, prospects for achieving their goals, their transformations, and engagement with other agencies and partnerships. It also illuminates how social partnerships need to operate, how they respond to changing circumstances, and how they might be best supported by external sponsoring agencies to realise their purposes in sustainable ways. The dimensions partnership work identified comprised: (a) cultural scoping work; (b) connection-building work; (c) capacity-building work; (d) collective work; and (e) trust-building work (Billett et al., 2005).

The practices that underpin these dimensions of partnership work were also identified through the analyses. They included how the partnerships might come to manage the contested relationships and diverse imperatives that are played out in social partnership work.

\section{Principles and practices of effective partnership work}

From the analysis of the interview data, five sets of principles were identified as being effective in guiding both initial and ongoing partnership work. These are building and maintaining: (i) shared purposes and goals; (ii) relations with partners; (iii) capacities for partnership work; (iv) partnership governance and leadership; and (v) trust and trustworthiness. These principles are enacted around five dimensions of partnership work and manifest in a set of practices aligned to them. This work is best realised through the work processes within social partnerships, supported and informed by external sponsors and the adoption of particular variations and emphases within social partnerships over time. These five principles are now elaborated in turn. In each instance, the principle is described, followed by a justification and elaboration of the principle from the data. Sometimes a direct quote from interview transcripts is used (with the source within the partnership being referred to), whilst elsewhere aggregations of data from the sources are presented.

Building and maintaining shared purposes and goals

Building and maintaining shared purposes and goals was an imperative, referred to across social partnerships. It often initially involves identifying the partners' interests and concerns, and developing a framework for collectively realising these as goals. Over time and beyond initial development, focus on shared purposes and goals can helpfully comprise 
the partners actively reflecting upon, reviewing and revising goals, identifying achievements, and renewing commitment. So these goals were not fixed, but evolved through engagement and interaction and the working through of localized agendas.

In forming social partnerships, a need was identified in the community/regional forum/sector for individuals to work collectively. This comprises a need that mobilises individuals locally and often voluntarily to take action to achieve particular goals (i.e., in response to a local problem or need). For instance, a training cafe for disadvantaged learners brought together a range of affiliated interests in the local area, who collaborated and augmented each other's contributions. Other instances of localized concerns were those associated with young school leavers, concerns about lack of infrastructure and opportunities for young people, and employee needs of local hospitality enterprises. The same kinds of processes occurred within a community on the fringe of a metropolitan city and a provincial city. Here, the community concern focused on, respectively, the lack of opportunities and infrastructure for young people, and support for disability workers in the provincial region community. In this third instance, there was disappointment with the quality of training provided in the region and its cost through the national provision of vocational education by the local technical and further education (TAFE) institute. This partnership also had a shared commitment to work with a newly appointed TAFE staff member who was seeking to work more effectively within the disability community. So here, there were two levels of engagement: first, a common set of concerns and second, a willingness to work with TAFE to improve the provision of disability training.

However, the common problem or issue might elicit quite different and potentially contradictory responses from participants within the community. For instance, in one project there were tensions between providing skilled workers for mine site operations and maintaining the community of a mining town. The mines are increasingly favouring the employment of 'fly-in and fly-out' workers (i.e., those who do not reside in town). While one set of local interests (i.e. the mine sites) is concerned to utilise this kind of skilled labour, another partner (i.e. local government) is concerned that it stands to degrade and depopulate the community. Hence, while there is a need to identify common bases and goals for proceeding, then maybe a lack of consonance in approaches to addressing these goals.

So, while social partnerships might focus on a common problem, partners likely bring distinct perspectives about the problem and how it can be solved and what costs are sustainable; in this and other partnerships, there may be different and competing interests being enacted. Therefore, it should not be assumed that social partnerships in their formation and evolution are benign, as they may comprise different interests which may be more or less consistent with the partnerships' publicly stated, consensus-derived goals. While problematic, this history of community concern can be empowering in the first instance and essential for the difficult tasks of building on this sentiment and the effort to sustain the social partnership over time. A belief that something can be achieved through collective work (i.e., that young people can be helped, that education can make a difference) is likely to be important for sustaining interest, particularly volunteer effort. Consequently, to buoy this belief over time, as one LLEN informant commented, "... there needs to be celebration of a few key successes". Early successes, even of a modest or piloting kind, may be a basis for sustaining the shared interest to coalesce and/or invigorate partners, and to offer a basis for a focus on common rather than sectoral concerns.

The process of developing a strategic plan, which is realistic in achieving its goals, can also be a useful device to build trust and encouraging partnerships within the 
community and overcoming institutional tension, according to a LLEN participant. Changes in partners' practice that facilitate and demonstrate a commitment to the partnership's goals are indicative of the building of common goals and trust. For instance, at one college they decided to embed the work experience activities in the overall school curriculum and provide flexible arrangements so that the students' work experience would not jeopardise other aspects of their studies. In this way, the college changed its practices to respond to the needs of students and employer partners outside of the school. Reciprocity in partners' needs was also acknowledged and exercised (e.g., local government connecting with community through LLENs; employers securing potential employees through work placement programs). Part of this task is to reach out, engage and include the views of those who normally would not have a voice (e.g., young people, drug users, and people in public housing), as their contributions might be central to achieving the partnership's core goals. It is these voices that might also remind the partnership of the core goals when issues of partnership administration and processes come to dominate the work of the social partnership.

In this way, an important principle for establishing and maintaining social partnership is identifying shared purposes and goals and focusing social partnerships activities (i.e. partnership work) on those imperatives.

Building and maintaining relations with partners

Building relations with community partners initially involves building trust and commitment, encouraging participation, and developing processes that are inclusive and respectful. Over time, it likely involves the need for endorsing and consolidating existing relationships, recognising partners' contributions, and facilitating new and strategic relationships, in order to maintain those relations.

Mutual respect needs to be exercised between partners to build and maintain relationships. This includes being open and honest, particularly about relationships (community partnership informant). It was held by a LLEN informant that "personal networks are most useful. Attempts at formal networks, sanctioned by government funding, do not work". Permitting, at the local level, social partners to shape what kind of partnership they want (e.g., represented by service or region) and also what role they should take within partnership activities (enacted partnership) was reported as being empowering. As one of the LLEN informants suggested, "The big issue was that the LLEN was imposed. No one was willing to participate with top-down processes". This empowerment might extend to revising, overturning or remaking centrally-devised rules that are impractical or unworkable (negotiated partnership informant) thereby providing a means to engage partners in ways that meet local needs. A strong, cohesive steering group where members were empowered by the process (community partnership informant) was reported as being helpful in developing and maintaining relations with partners at the local level through the pertinence of processes and the level of engagement.

These relations extended to sponsors and influential participating institutions. Commonly it was stated that once the leaders of participating institutions had committed to the social partnership then it was much easier for it to progress, as members who were institutional representatives could proceed in making decisions and commitments on behalf of those institutions.

The process of building relations with partners, however, should not be wholly premised on the presentation of information. Instead, this relationship building best arose 
through consultations that are underpinned by and model the sentiment "you can influence what happens here" (enacted partnership informant). At the same time there was a need to disabuse partnership members of the view that the partnership was a means of accessing additional resources for themselves and their institutions. Engaging with and keeping partners informed, working through disagreements and resolving all reconciling differences and concerns as they arise (e.g. "make sure no one goes off in anger" (LLEN participant)) was also important in making a social partnership work. Moreover, to sustain the relations underpinning the social partnership, it is necessary "to celebrate a few key successes - and to now understand what is required for future successes" (LLEN informant). Furthermore, against sponsors' need for expediency and quick goals, "Taking time to build trust and being patient in making sure that all parties are being heard" is important (community partnership informant). The instance of the social partnership supporting the cafe for disadvantaged learners had worked with the school for a number of years prior to a formal partnership being established. This partnership was premised on the trust and familiarity that arose through years of previous successful collaborations. That is, a history of working together may well be required for effective and trusting partnerships to evolve. A consistent concern expressed by the LLENs was that the environmental scans that they had to undertake early in their formation to identify and map local need were subject to a tight and early deadline, premised on governmental imperatives. This resulted in incomplete and sometimes hurried consultations. While providing useful information, if hurried and not widely inclusive, the processes used in these scans may not been wholly instrumental in achieving salient goals associated with partnership development: building relations with potential partners.

The incremental introduction of new processes and goals is likely to assist manage the staged development of social partnerships, with their introduction being premised upon the antecedents comprising their origins and auspicing. Imposed implementations of agendas for change threaten the capacity of the partners to cope. Prior and negative experiences of institutional arrangements (e.g., TAFE, schooling) likely shape volunteers' responses to their engagement with these institutions. All of these underpin the importance of building and maintaining relations with the partners that comprise these social partnerships.

Building and maintaining capacities for partnership work Building the capacities for partnership work initially involves engaging partners in the collective work of the partnership, through developing the infrastructure and resources needed to achieve goals. Over time, it includes securing and maintaining partners who engage effectively with both community and external sponsors, and managing the infrastructure required to support staff and partners.

Both 'enacted' and 'community partnerships' may require support or specific interventions to develop the capacity for partnership work. There may well be a strong sense of collectivity and a readiness of individuals/organisations to participate effectively as partners. However, building the capacity to affect effective partnership work is also essential for their development and continuity. Yet, much of this capacity can be developed through engaging in partnership work supported by an ethos that prizes engagement and acknowledging this engagement as a learning process and social partnerships as a learning space. The importance of having collective processes for learning the capacities for partnership work is illustrated through the following accounts of learning in which 
participants suggested that: "Continuing to learn together community skills"; "gaining confidence to influence bureaucrats and gain more funds"; "sharing feedback about everything, often spiritual experience -- becoming the best that they could for the good of all" and "using skilled facilitators to workshop issues and gain consensus and mutual support" (community and enacted partnership informants). These are all important capacities, but may be present within social partnerships as they form in different degrees and are required to be fostered in different ways. Nevertheless, their salience to partnership work underlines the importance of social partnerships offering an environment for the learning of these capacities.

Developing the capacities for partnership work is also aligned to achieving strategic goals. These can include ways of overcoming the problem of being ignored and underresourced, and also the requirement to compete for funds with others who have similar goals and concerns (community partnership informant), and developing capacities to work effectively with partners (e.g., college staff gaining certificates in training and assessment and accruing work experience (enacted partnership informant).

Certainly, identifying appropriate individuals to participate, suitable goals and organising effective meetings was held to achieve the greatest effect when dealing with dominant partners who might try to secure particular interests (Wide Bay Coalition). This included finding ways to demonstrate to sponsoring agencies that a true partnership has to have a 'bottom-up' rather than 'top-down' style in order to gain commitment from the community it serves, thereby achieving the goals of the centre (negotiated partnership informant). For instance, when negotiating with partners and sponsoring agencies about resources designed for metropolitan centres not being useful in regional centres, it was necessary for the case to be understood. Also, in the case of a partnership which has its genesis in the community there is the importance of building the capacities to effectively engage with government as "understanding how power works and who has it" (community partnership informant) was important to this partnership securing it goals.

In these ways, developing the capacity for partnership work becomes part of partnership work and is essential for their development and continuity over time.

Building and maintaining partnership governance and leadership Initially, building governance and leadership was reported as involving formulating and adopting consistent, transparent and workable guidelines and procedures for the partnership work and enactment of leadership. Over time, it included developing and supporting close relations and communication between partners, and effective leadership.

Effective governance is seen as important for the development of social partnerships and their continuity over time. Early in their development and at later stages, establishing ground rules for governance and being consistent with their application were commonly held to be important principles. However, the process of establishment and the changes to the roles should be progressed in ways that are consensual (negotiated partnership informant). Similarly, it seems essential that any board or committee of management understands and is clear about its purposes, and where the parameters of its influence and activities reside - this includes an understanding of what it is not about. Also, aligned with clarity of purpose is understanding the role of other agencies that have similar or complementary roles, and how the actions of the social partnership will influence relationships with those agencies (enacted partnership informants). Furthermore, there is a need to understand and rehearse the bases upon which the partnership has been founded and 
be sensitive to those actions that will likely cause mistrust and concern elsewhere within the community. Hence, the governance and leadership of social partnerships need to be open to building trust and communicating freely and fairly with their constituent community. This needs to extend to encouraging discussion and alternate viewpoints, and having mechanisms that can challenge or question the consensus within the social partnership.

A leadership group or board of management likely needs to understand its role and be reminded of and explicitly rehearse the interests that underpin its operation. These are reported as being sometimes forgotten as the day-to-day administration concerns of the social partnership come to predominate. Indeed, volunteers begin to resent too much time being taken with partnership administrative matters, rather than the purposes for which the partnership was established. Those in governance roles also need to be explicit about and mindful of the balance of interests reflected in their membership of the board. They should avoid this involvement being seen as operating in favour of or privileging particular interests (enacted partnership informant). There was also a suggestion that the size and composition of the committees or boards of management need to be commensurate with the particular social partnership, its goals and constituents. Prescribed arrangements are understandable from the sponsor's perspective, but require flexibility in order to meet local concerns and manage participation. This was an issue mentioned by several of the LLENs. Elsewhere, analogously, it was suggested that a "strong local reference group, local residents and talented local employees of Community Renewal Team" were essential in the formation of social partnership (community partnership informant). So, there is an important role for leadership and governance. Certainly, given the likely diverse base of interests and institutional capital invested in social partnership, it is probably important to have a consistent, public and clear purpose which can be negotiated by partners yet stands as a key set of purposes. There "needs to be a clear vision and how that vision is to be achieved. It needs to be relevant more relevant -- relevant industry, relevant to educational providers and relevant to young people" (enacted partnership informant).

So, it seems that in different ways and forms, social partnerships require governance and leadership that are pertinent to their structure, purposes and goals and that this governance and leadership are essential for the effective formation and continuity of social partnership, through engaging in, being responsive to and inclusive with its membership.

Building and maintaining trust and trustworthiness

Building trust initially involves establishing processes that engage and inform partners, including encouraging cooperation and collaboration. Over time, it involves focusing on partners' needs and expectations, and ensuring that differing needs are recognised and addressed. Throughout the above processes, the issue of trust and its development and continuity has been brought to the forefront. Therefore, a key principle for and practice of social partnerships is the building of trust through processes that engage, inform and are informed by participants" contributions. Yet, the "establishment of trust took a long time, antecedents include a highly competitive environment in the area of youth support" (enacted partnership informant). In some cases, the partnership itself was premised on a history of relationships premised on trust. This was particularly the case in those partnerships categorised as community and negotiated, where familiarity and trust were underpinned by a history of a form of partnership working. In particular, a key statement about trust and commitment was identified when partners were willing to "give something 
up" to participate in the partnership. This was taken as providing evidence of a commitment that leads to trust and openness within the partnership. For instance, it could be seen that there was sometimes too little evidence that participating organisations were willing to change their organisational strategic plans to align with the LLENs' plans and goals.

Achieving this trust and trustworthiness requires engaging with local communities/partners in ways that build their confidence with the social partnership. It was claimed that even the development of a strategic plan that is realistic in achieving its goals, is important in building trust and encouraging partnerships within the community and overcoming institutional tensions (enacted partnership informant). That is, the process of developing the strategic plan offered a vehicle to do more than merely provide information, but canvassing and responding to their suggestions and needs. An informant from a negotiated partnership suggested that it was essential to their success that they stuck to the promises they had made to the networks and partners. "Ultimately, it is not what is written on pieces of paper that make commitment, but how individuals want to engage and lock themselves in to the partnership". This informant also suggested that being honest, not having too high expectations, using a polite style, not being too critical, demonstrating and exercising respect of people, including those from the 'other side' and engaging with those who were not forthcoming or inclined to participate were necessary in building an effective regionally based social partnership.

Similarly, from an enacted partnership perspective, it was suggested that "the establishment of trust is likely to come through its capacity to support young people (i.e., achieve its goal). For instance, the current project on manufacturing work and attempting to change the community's perspective about this kind of work could have positive outcomes for the community and the local kids". In this way, locally available evidence of commitment, goodwill focused on the partnerships core goals will likely convince and engage even skeptical participants. This illustrates the importance of building and sustaining trust with the local community as a key principle for partnership development and continuity.

Of course, these sets of principles and their associated practices are seen as 'ideals' to be worked towards and to advance as desirable outcomes, albeit in environments that while purporting to be focused on shared interests and concerns, are often highly contested. Partnerships will not always be successful, and some, perhaps are not worthy of success. This is perhaps particularly the case when central agencies co-opt local interests and act to achieve policy goals which may be at odds with those of the community. These principles and their elaborations have been endorsed by participating social partnerships as reflecting the kinds of principles that lead to development of and sustaining of effective partnership work (Billett et al., 2005).

\section{Social partnerships in prospect}

In these ways, this project identified and verified principles articulating the potential of social partnerships to work effectively locally in enacting important localized educational purposes. It seems that they can work well to intuit, articulate and respond to local needs and capacity building - the very purposes that vocational education and training, and education generally, are often directed towards. However, social partnerships do not just happen as result of external demand: they have to be enabled and supported. Social partnerships, themselves, need to initiate, develop and sustain the capacities required for partnership work. There is sometimes slippage between supporting a social partnership for 
its own sake and the purposes for which it was set up. Articulation and restatement of purpose were reported as frequent habits in social partnerships to keep purpose in sight.

It was found that, while it is possible to define a social partnership according to the genesis of its formation, the qualities and forms of social partnerships are not fixed. They take on different forms as they evolve. The genesis of the social partnership and the antecedent conditions for its existence shaped the scope of partnership work undertaken. It follows that government and non-government agencies seeking to use social partnership for policy or program purposes should aim to become partners and engage in partnership work, rather than attempting to direct and control the participants. They might also find evaluating social partnerships could be best achieved through appraising the quality and sustainability of partnership work, through the principles and practices articulated above and being patient about tangible outcomes that will take time. Also, in their initial evaluations, they might focus on the processes being used by partnerships to develop and sustain their working. However, often there is a level of political expedience - the political heart beat - that will not tolerate such patience.

While partnership work is the obvious activity within social partnerships, the qualitative character of that work is also evident in many other work and community settings. Understanding partnerships and partnership work within distinctive localised needs may provide a way of more tightly contextualising and conceptualising the motivations, goals, work practices, resources and definitions of success. Other policy considerations include using these principles and practices within social partnerships when developing vocational curriculum that reflects both localized as well as national imperatives and priorities (Billett, 2000).

In conclusion, unless considerations of the kinds advanced here are enacted by governmental sponsors, it seems likely that these social partnerships will become focused on conformity, compliance and control (Coffield, 2000), the very issue that has seen the political imperatives evolve. Given that vocational education provision is often supported by social partnerships, as reflected by many of the partnerships canvassed in this study, the nature of partnership work to secure robust social partnerships is of interest and relevance to education. Importantly, these principles provide a platform to make judgments about the efficacy of partnership work, which otherwise is prone to being only judged on the basis of measurable outcomes.

Acknowledgements. This research was funded by the Australian Research Council and the National Vocational Education and Training Research and Evaluation Program of the Australian National Training Authority/Department of Education, Science and Technology as administered by the National Centre for Vocational Education Research. We acknowledge the contributions of the ten social partnerships that permitted us to engage them in interviews and in reflecting upon our findings. Also, the detailed and thoughtful comments of the reviewers assisted in the revision of this paper.

\section{References}

Australian National Training Authority (2003) Shaping our Future: Draft National Strategy for Vocational Education and Training, 2004-2010 (Brisbane: ANTA).

Billett, S., Clemans, A. \& Seddon, T. (2005) Forming, Developing and Maintaining Social Partnerships (Adelaide: NCVER).

Billett, S. (2000) Defining the demand side of VET: industry, enterprises, individuals and regions. Journal of Vocational Education and Training, 50(1), 5-30. 
Billett, S. \& Seddon, T. (2004) Building community through social partnerships around vocational education and training. Journal of Vocational Education and Training, 56(1), 51-67.

Cardini, A. (2006) An analysis of the rhetoric and practice of educational partnerships in the UK: an arena of complexities, tensions and power. Journal of Education Policy, 21(4), 393-415.

Coffield, F. (2000) Lifelong learning as a lever on structural change? Evaluation of white paper: Learning to succeed: a new framework for post-16 learning. Journal of Education Policy, $15(2), 237-246$.

Field, J. (2000) Governing the ungovernable: why lifelong learning promises so much yet delivers so little. Educational Management and Administration, 28(3), 249-261.

Green, A., Wolf, A. \& Lehney, T. (1999) Convergence and Divergence in European Education and Training Systems. London: Institute of Education.

Jessop, B. (1998) The rise of governance and the risks of failure international. Social Science Journal, 155, 28-43.

Kosky, L. (2001) Response to Kirby Report - Overview of the Government's Response to the Kirby Report. Available online at http://www.det.vic.gov.au/det/postcomp/govresponse.htm (accessed 4 August 2006).

O’Donoghue, D. (2001) A little TLC works wonders. Education Times, 17, 13.

Queensland Community Services and Health Industries Training Council (QCS\&H ITC) (2005)

Getting into partnership work: An activity session. Annual Gathering of the Integrated Skills Development Networks, Brisbane, 22 March.

Putnam, R. (1993) Making Democracy Work: Civic Traditions in Modern Italy. (Princeton, NJ: Princeton University Press).

Rees, G. (1997) Vocational education and training and regional development. Journal of Education \& Work, 10(2), 141-149.

Seddon, T., Billett, S. \& Clemans, A. (2005) Navigating social partnerships in VET: central agencies - local networks. British Journal of Sociology of Education, 26(5), 567-584.

Seddon, T. \& Billett, S. (2004) Social Partnerships in Vocational Education: Building Community Capacity (Adelaide: National Centre for Vocational Education Research).

Seddon, T., Billett, S. \& Clemans, A. (2004) Politics of social partnerships: a framework for theorising. Journal of Education Policy, 19(2), 123-142.

Seddon, T., Fischer, J., Clemans, A. \& Billett, S. (2002) Evaluation of First Phase of LLENs enactment. Victorian Learning and Employment Skills Commission, Department of Education and Training, Melbourne, Victoria, Australia.

Taylor, A. (2006) 'Bright lights' and 'twinkies': career pathways in an education market Journal of Education Policy, 21(1), 35-57.

UNDP (1997) Capacity assessment and development: in a systems and strategic management context. Technical Advisory Paper No 3, Management Development and Governance Division, Bureau for Development Policy, United Nations Development Programme, New York. 